\title{
Detection of transgene in early developmental stage by GFP monitoring enhances the efficiency of genetic transformation of pepper
}

\author{
Min Jung $\cdot$ Sun Hee Shin $\cdot$ Jeong Mi Park $\cdot$ \\ Sung Nam Lee $\cdot$ Mi Yeon Lee $\cdot$ Ki Hyun Ryu • \\ Kee Yoeup Paek $\cdot$ Chee Hark Harn
}

Received: 13 September 2010/Accepted: 31 December 2010/Published online: 25 January 2011

(C) The Author(s) 2011. This article is published with open access at Springerlink.com

\begin{abstract}
In order to establish a reliable and highly efficient method for genetic transformation of pepper, a monitoring system featuring GFP (green fluorescent protein) as a report marker was applied to Agrobacteriummediated transformation. A callus-induced transformation (CIT) system was used to transform the GFP gene. GFP expression was observed in all tissues of $\mathrm{T}_{0}, \mathrm{~T}_{1}$ and $\mathrm{T}_{2}$ peppers, constituting the first instance in which the whole pepper plant has exhibited GFP fluorescence. A total of 38 $\mathrm{T}_{0}$ peppers were obtained from 4,200 explants. The transformation rate ranged from 0.47 to $1.83 \%$ depending on the genotype, which was higher than that obtained by CIT without the GFP monitoring system. This technique could enhance selection power by monitoring GFP expression at the early stage of callus in vitro. The detection of GFP expression in the callus led to successful identification of the shoot that contained the transgene. Thus, this technique saved lots of time and money for conducting the genetic transformation process of pepper. In addition, a co-transformation technique was applied to the target transgene, CaCS (encoding capsaicinoid synthetase of Capsicum)
\end{abstract}

M. Jung · S. H. Shin · J. M. Park · C. H. Harn ( $)$

Biotechnology Institute, Nongwoo Bio Co., Ltd,

Yeoju, Gyeonggi, Korea

e-mail: chharn@nongwoobio.co.kr

S. N. Lee $\cdot$ M. Y. Lee $\cdot$ K. H. Ryu

Department of Environmental and Life Sciences,

Seoul Women's University, Seoul, Korea

K. Y. Paek

Department of Horticultural Science, Chungbuk University, Chungbuk, Korea along with GFP. Paprika varieties were transformed by the $C a C S:: G F P$ construct, and GFP expression in callus tissues of paprika was monitored to select the right transformant.

Keywords GFP expression - Callus induction · Co-transformation $\cdot$ Pepper $\cdot$ Agrobacterium

\section{Introduction}

Green fluorescent protein (GFP) is a fluorescent protein expressed in jellyfish, Aequoria victoria, and its fluorescence was first used as a marker for gene expression to highlight sensory neurons in nematodes (Chalfie et al. 1994). Since the role of GFP is to transduce the blue chemiluminescence of the aequorin protein into green fluorescent light by energy transfer (Rosario et al. 1995; Hanson and Köhler 2001), the GFP gene has become a useful tool for making chimeric proteins that are linked to other proteins for use as fluorescent protein tags. Such chimeric constructs are expressed in bacteria (Leff and Leff 1996), yeast (Spellig et al. 1996), Drosophila (Yeh et al. 1995), C. elegans (Chalfie et al. 1994), zebrafish (Higashijima et al. 1997), and mammalian cells (Zolotukhin et al. 1996).

Although GFP is the most common reporter gene used in plant cell biology (Leffel et al. 1997; Dixit et al. 2006; Haseloff and Siemering 2006), its first application to plants was in the transformation of maize mesophyll protoplasts and intact tissues of Arabidopsis leaf and root by microprojectile bombardment (Sheen et al. 1995). Fluorescence was detected in maize and Arabidopsis upon excitation with UV or blue light even in the presence of blue fluorescence from the vacuole or red chlorophyll autofluorescence from chloroplasts. 
This technique can also be used to monitor the transformation of tissues at the early stage of development in vitro by observing GFP expression (Ghorbel et al. 1999; Elliot et al. 1999; Chung et al. 2000; Vain et al. 1998; Stewart 2001; Majid and Parveez 2007). When a single cell stably expressing the GFP gene continuously develops to a callus mass under proper selection medium, GFP is expressed in the whole callus tissue. Then, GFP-expressed callus mass can be selected under a microscope and applied to shoot induction. The shoot grown from the callus expressing GFP can also be easily detected. This technique can be applied to plants in which the transformation rate is low or the rate of false-positive-induced shoot is rather high.

The transformation of chili pepper using a method called CIT (callus-induced transformation) has been established (Lee et al. 2009), and the transformation rate is between 0.43 and $0.66 \%$ depending on the genotype. Still, several obstacles to the genetic transformation of pepper remain. Firstly, the transformation rate of some lines such as habanaro is extremely low. In other words, the genetic transformation methods and conditions must be modified for each line. Secondly, our group (CH Harn's lab) has been the only one to generate transgenic peppers routinely; many laboratories could not perform the CIT method successfully due to the high level of skill required. Thirdly, since the inbred lines required by the CIT method are not generally feasible to public users, a better and easier way to obtain the transformed shoot is necessary.

In order to enhance the selection of transformed peppers, a selection method was developed by monitoring GFP expression after Agrobacterium-mediated transformation. In this study, the GFP transgene was transformed through CIT using an Agrobacterium strain (EHA105) for the genetic transformation of pepper. Callus induction and shoot induction from the callus were observed by monitoring GFP expression. Indeed, the chance of selecting transformed pepper shoot expressing the GFP transgene was much higher than that of obtaining transformed pepper shoot through an ordinary CIT method. This technique was also used to monitor genetic transformation of paprika by co-transformation of $\mathrm{CaCS}$ gene and it helped the transformation successfully.

\section{Experimental procedures}

\section{Pepper lines}

Five commercially available chili pepper inbred lines (P915, P318, P319, P409 and P410, properties of Nongwoo Bio Co.) and three sweet pepper cultivars (Paprika: Midas, Maximalia and Special) were used for the genetic transformation.
Genetic transformation of pepper

Seeds from the inbred lines were surface-disinfected in 95\% $\mathrm{EtOH}$ for $30 \mathrm{~s}$ and $25 \%$ bleach (Yuhanrox) for $30 \mathrm{~min}$, and then rinsed three times with sterilized water. The sterilized seeds were placed in 1/2 MS medium (Murashige and Skoog 1962) and allowed to germinate in the dark at $25^{\circ} \mathrm{C}$ for $8-10$ days. Cotyledons from 3-day-old seedlings were excised and used as explants for regeneration and transformation. All procedures for the genetic transformation of pepper were performed according to the paper written by Lee et al. (2009). For GFP expression, a vector containing the $35 \mathrm{~S}$ CaMV promoter along with NPTII for kanamycin selection and the GFP gene (mGFP5ER; U87974.1; 743 bp) was transformed into Agrobacterium EHA105 (Fig. 1). Another vector (pK7WG2D-CaCS, data not shown) was prepared for co-transformation with the GFP gene and CaCS gene (Capsicum annuum capsaicinoid synthetase; AY819027, provided by Dr. Byung Dong Kim). After the young seedlings had been successfully transformed, they were transferred to zippy pots in a growth chamber for $1-2$ weeks and finally grown in a plastic house at $25 \pm 10^{\circ} \mathrm{C}$.

\section{Observation of GFP expression}

To observe GFP expression, two different methods were applied. For small samples grown in a petri dish or small culture bottle, pictures were taken by fluorescence
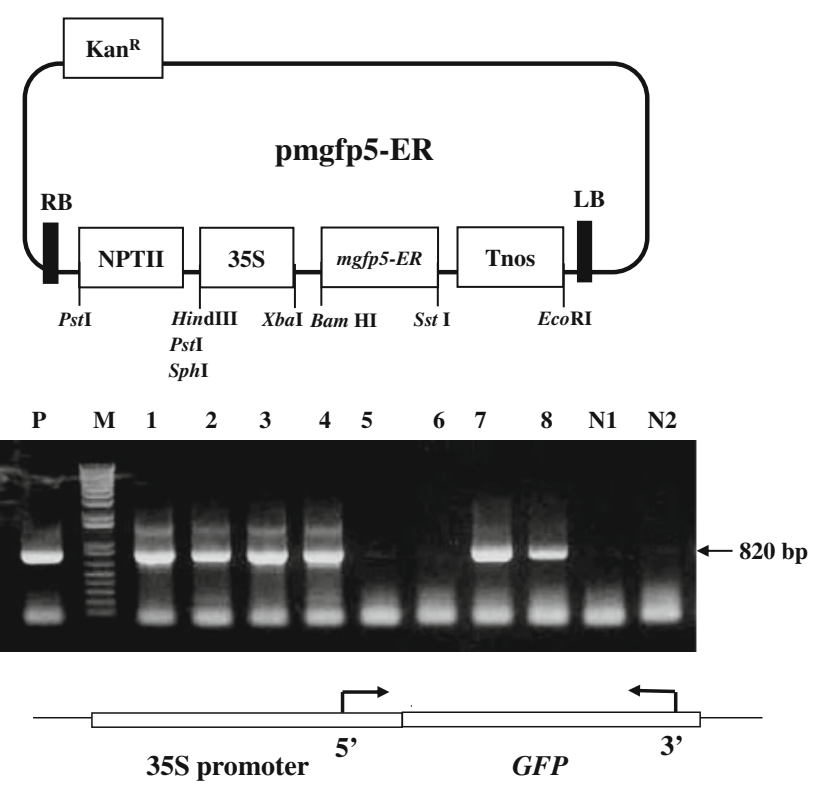

Fig. 1 Vector for transformation of GFP transgene and PCR analysis of $G F P$-expressing peppers. $P$ bacterial cells harboring GFP, $M$ molecular marker; $1-8$ transformed $\left(\mathrm{T}_{0}\right)$ peppers, $N 1$ and $N 2$ non-transformed 
microscopy (Olympus BX51; Tokyo, Japan) equipped with a U-MNIBA filter (BA 515-550 nm; Olympus) attached to a digital camera. For bigger and taller samples, plants were laid on the GFP device (DLS GFP-MDS-96; BLS, Budapest, Hungary) which is $80 \mathrm{~cm}$ tall and has 8 light sources with 96 ultra-bright blue LEDs or LAS-3000 luminescent image analyzer (Rayteck Scientific, Sheffield, UK). Pictures were taken through a GFP filter (FHS/EF-3GY1; BLS) attached to a digital camera. For the resolution of GFP expression from transgenic pepper, a confocal image analyzer program (Carl Zeiss LSM Browser Bersion 2.80.1123; Jena, Germany) was used to detect the green color which appeared only under GFP expression.

\section{PCR and RT-PCR}

To detect the transgene in transformed pepper plants by PCR, the total DNA of transformed pepper was isolated using a DNA extraction kit (iNtRon Biotechnology, http://www.intronbio.com). The PCR primer sequences detecting GFP ( $820 \mathrm{bp}$ ) were $5^{\prime}$ sense orientation, $5^{\prime}$-ATG ACGCACAATCCCACTAT- $3^{\prime}$ (sense: the $35 \mathrm{~S}$ promoter region at 3,185-3,204 bp of accession number X84105) and $3^{\prime}$ antisense orientation, $5^{\prime}$-CATGTGGTCTCTCTTTT CGTTGG-3' (antisense: GFP gene at $737-715 \mathrm{bp}$ of accession number U87974.1). To detect the PCR product (805 bp) of the $C a C S$ gene, $5^{\prime}$ sense orientation, $5^{\prime}$-ATG ACGCACAATCCCACTAT- $3^{\prime}$ (sense: the $35 \mathrm{~S}$ promoter region at 3,185-3,204 bp of accession number X84105) and $3^{\prime}$ antisense orientation, 5'-TCGTACGCACTCGTT GAGATC-3' (antisense: $\mathrm{CaCS}$ gene at 2,590-2,570 bp of accession number AY819027) were used. PCR analysis was carried out using these primers in 0.65 and $299 \mu \mathrm{M}$ dNTP, $1 \mathrm{U} / \mu \mathrm{M}$ of Taq DNA polymerase (BioLabs, http:// www.neb.com) in $50 \mathrm{mM} \mathrm{KCl}, 1.5 \mathrm{mM} \mathrm{MgCl}_{2}$ and $10 \mathrm{mM}$ Tris- $\mathrm{HCl} \mathrm{pH}$ 8.3. The PCR program consisted of 35 amplification cycles of, 94,55 and $72^{\circ} \mathrm{C}$ for $1 \mathrm{~min}$ each.

RT-PCR analysis was carried out using total RNA isolated using the Trizol reagent (Life Technologies; Chomczynski and Sacchi 1987) and treated with RNase-free DNase (Promega). The PCR primer sequences used for detecting GFP were: $5^{\prime}$-TCTGTCAGTGGAGAGGGTG AAGG-3' (sense: GFP gene at $82-104$ bp of accession number U87624) and 5'-GTACACCAGAGAGAAAA GCAACC-3' (antisense: GFP gene at 654-632 bp). About $1 \mu \mathrm{g}$ of total RNA was used for a reverse transcription reaction in a final volume of $20 \mu \mathrm{l}$, and the reaction mixture was subjected to PCR amplification with initial denaturation at $94^{\circ} \mathrm{C}$ for $30 \mathrm{~s}, 55^{\circ} \mathrm{C}$ for $30 \mathrm{~s}$ and $72^{\circ} \mathrm{C}$ for $1 \mathrm{~min}$ with 35 cycles. The identity of the RT-PCR product was confirmed by DNA sequencing (data not shown). The PCR and RT-PCR products were loaded onto $1 \%$ agarose gel.
Southern and western blot analyses

For genomic Southern blot analysis, the DNA of $\mathrm{T}_{0}$ peppers was isolated using the method described by Sambrook et al. (1989). Briefly, $30 \mu \mathrm{g}$ of DNA was digested with BamHI and $X b a \mathrm{I}$ (enzymes that do not cut the insert) and then fractionated on $0.8 \%$ agarose gel. Southern blotting was performed as previously described (Sambrook et al. 1989) using Hybond N membranes (Amersham Biosciences, http://www. amershambiosciences.com), followed by hybridization with

${ }^{32} \mathrm{P}$-labeled probe containing the GFP gene (U87974.1) as instructed by the manufacturer (Amersham Biosciences, http://www.amershambiosciences.com). For the western blot analysis, total proteins isolated from leaves were separated on $12 \%$ SDS-polyacrylamide gels and transferred onto nitrocellulose membranes. Membranes were probed with $\mathrm{N}$-terminal anti-GFP antibody (Sigma product number: G1544), followed by the secondary antibody, anti-rabbit IgG (FC) AP conjugate (Promega catalog number S3731). To visualize antibody-specific proteins, the method modified by Park et al. (2005) was used.

\section{Results and discussion}

Monitoring callus, shoot and organs by GFP expression

Callus-induced transformation (CIT) is a previously developed method in which a callus is induced after which a shoot forms from the callus (Lee et al. 2009). This method was established by modifying the callus-mediated shoot formation method (Lee et al. 2004). Although CIT works well, obstacles still remain. For example, the selection efficiency of obtaining a transformed shoot from non-transformed shoots is low. Shoots are easily formed directly from the cut tissue of cotyledons, and these direct shoots are, in most cases, false-positive. Once these shoots grow, they do not die even in the presence of a high concentration of kanamycin. In contrast, the indirect shoot grown from the callus has a high probability of being transformed (Lee et al. 2004, 2009). Therefore, questions can be raised as to how to distinguish a transformed callus from non-transformed calli and how to obtain a transformed shoot grown indirectly from the transformed calli. The detection of a transformed callus and shoot at the early stage of development is crucial to the genetic transformation of pepper. Indeed, this visual marker actually facilitates the identification of transformation at the early developmental stage (Ghorbel et al. 1999; Elliot et al. 1999; Chung et al. 2000; Vain et al. 1998; Stewart 2001; Majid and Parveez 2007).

To establish another technical breakthrough of pepper transformation along with the CIT method, GFP expression 
was monitored from the early developmental stage of the callus after induction. Callus formation was detectable by microscopy after 2 weeks in the selection medium (Fig. 2), and was even more clearly detected by GFP expression under a GFP filter. The transformed callus brightly expressing GFP grew continuously without fluctuations in GFP expression levels. Also, there were partly bright or partly green calli present, though these were not used for further selection. The GFP-expressing shoot was induced from the callus upon incubation in the shoot induction medium (Fig. 3). Compared to non-transformed shoot, GFP was expressed in the entire tissue of a 1-month-old transformed shoot. We used five different genotypes to test the rates of callus induction, shoot formation and transformation using the GFP gene. The callus induction rate ranged from 8.1 to $31.0 \%$ (Table 1) with an average of $13.5 \%$, and these rates were very similar to the previous work (Lee et al. 2009). The expression rate of GFP among calli was $36.1 \%$, suggesting that one-third of the callus could possess the transgene. In contrast, without observing GFP expression from the callus stage, it is impossible to know which callus could contain the transgene. Therefore, the selection power was in choosing the callus expressing GFP at the callus stage. Further, this selection power was directly related to the higher probability of obtaining the transformed shoot. The GFP fluorescent callus was selected and moved to new media and cultured. The shoot induction rate from the callus was $43.9 \%$ (Table 1), and this was much higher than the value that was demonstrated previously (8.52\%) (Lee et al. 2009). The reason for the higher

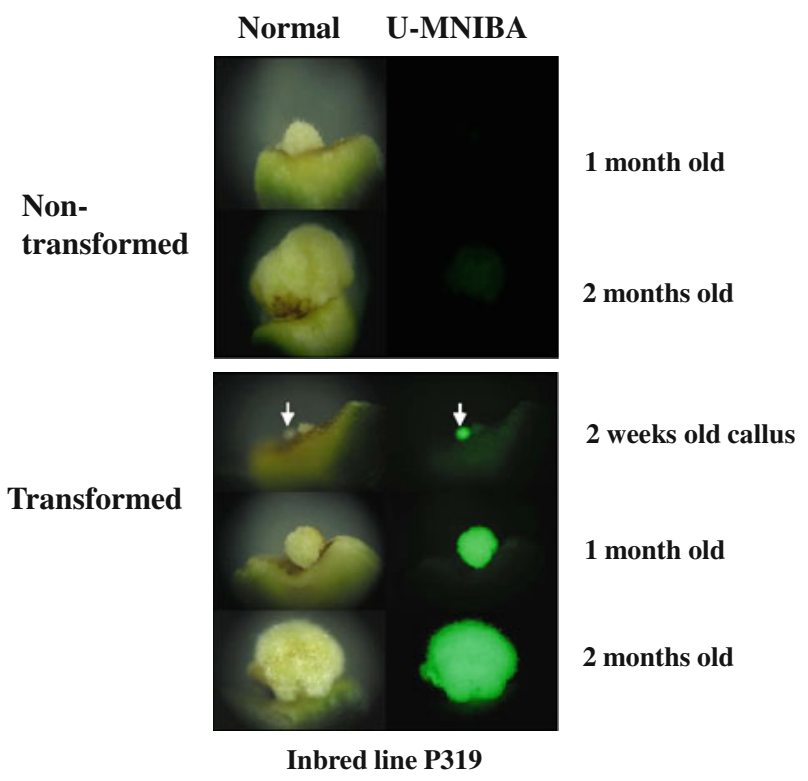

Fig. 2 Callus induction and growth. The pictures were taken by a fluorescence microscope $(\times 10)$ equipped with a U-MNIBA filter attached to a digital camera. Under the U-MNIBA filter, GFP expression is seen as a green color shoot induction rate was due to the fact that the selected callus expressing GFP was transferred into the shoot induction media directly to obtain the shoot with care. In contrast, the callus with no GFP expressing system would not be selected earlier and would be maintained for a longer time until the callus was grown properly to be transferred into the shoot induction media. In the case of pepper, a longer incubation time in the callus stage drags or reduces the shoot formation rate (Lee et al. 2004, 2009).

A total of 90 shoots were grown, all of them showing GFP expression. PCR analysis revealed that all the GFPexpressing shoots contained the GFP gene (data not shown). Therefore, the presence of GFP fluorescence in the shoot indicated that the shoot contained the transgene. Thirty-eight seedlings were then successfully transferred to a greenhouse. The rest of the shoots did not develop proper roots, or the seedlings were so weak that they did not survive when planted in the ziffy pot. The transformation rate calculated by the number of survived seedlings over the number of explants ranged from 0.47 to $1.83 \%$, depending on the genotype. However, the final transformation rate of the five different genotypes was an average of $0.9 \%(38 / 4,200)$. The previous data showed that the transformation rate of three different genotypes of pepper using the CIT method was on average $0.47 \%$ (Lee et al. 2009), and therefore this technology was about twice as efficient as the CIT method. However, if all the number of GFP-expressing shoots containing the transgene was counted, then the transformation rate would be $2.14 \%$ (90/ $4,200)$.

When the shoot was planted in the soil for further development, GFP was expressed by every organ: leaf, flower, green fruit, red fruit and seed (Fig. 4). However, the organs of the non-transformed pepper did not show GFP expression.

Southern blot analysis and segregation of transgene

To determine whether or not the GFP gene was inserted in the pepper genome, Southern blot analysis was performed. Thirty micrograms of genomic DNA isolated from $14 \mathrm{~T}_{0}$ (319 line) peppers was digested with BamHI and XbaI, followed by fractionation on $0.8 \%$ agarose gel. The Southern blot showed restriction bands of the GFP gene in the $\mathrm{T}_{0}$ peppers (Fig. 5). Lanes 1, 5, 6, 7, 9, 11, 12 and 13 contained single bands of various sizes. This indicates that each $\mathrm{T}_{0}$ pepper possessed one copy of the GFP gene in their genome, whereas the other lanes $(2,3,4,8$ and 14) contained possibly more than one copy. Lane 15 , a nontransformed control, did not show any band.

The $T_{0}$ plant of lane 6 was self-crossed, and $T_{1}$ seeds were obtained. Then, $\mathrm{T}_{1}$ seeds were germinated and exposed to UV light through a GFP filter. The seedlings 
Fig. 3 Shoot induction from callus. The pictures were taken by a fluorescence microscope $(\times 10)$ equipped with a U-MNIBA filter attached to a digital camera. Under the U-MNIBA filter, GFP

expression was seen as a green color

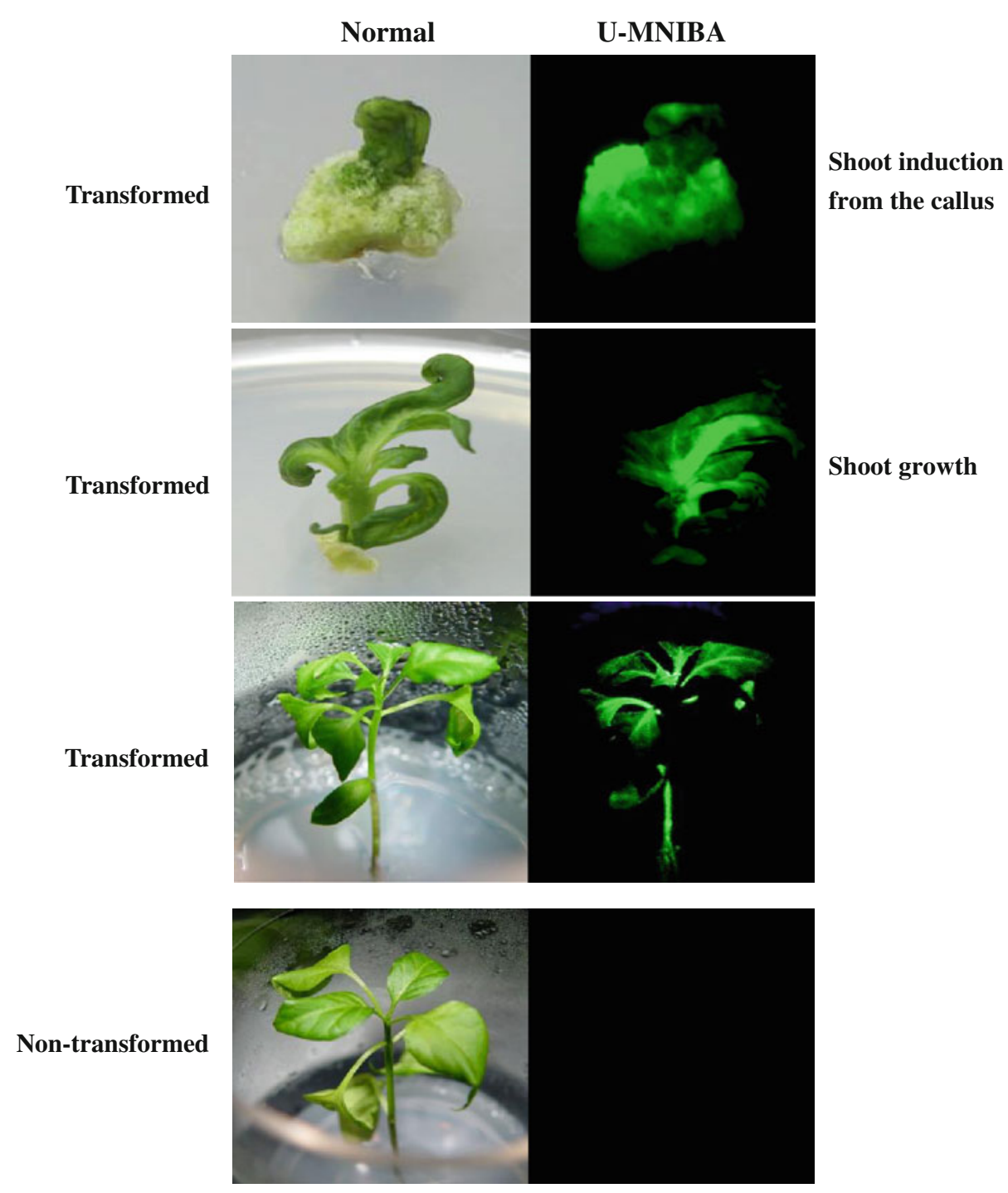

Table 1 Rates of induction, shoot formation and transformation in calli expressing GFP

\begin{tabular}{|c|c|c|c|c|c|c|}
\hline Genotype & $\begin{array}{l}\text { Number } \\
\text { of explants }\end{array}$ & $\begin{array}{l}\text { Number of } \\
\text { callus induced }\end{array}$ & $\begin{array}{l}\text { Number of callus } \\
\text { with GFP expression }\end{array}$ & $\begin{array}{l}\text { Number of shoots } \\
\text { with GFP expression }\end{array}$ & $\begin{array}{l}\text { PCR positive seedlings } \\
\text { transferred to green house }\end{array}$ & $\begin{array}{l}\text { Transformation } \\
\text { rate }(\%)\end{array}$ \\
\hline P915 & 1,400 & $202(14.4)$ & 68 & 23 & 15 & $15 / 1,400(1.07)$ \\
\hline P318 & 860 & $27(3.14)$ & 9 & 8 & 4 & $4 / 860(0.47)$ \\
\hline P319 & 600 & $186(31.0)$ & 82 & 40 & 11 & $11 / 600(1.83)$ \\
\hline P409 & 940 & 77 (8.10) & 27 & 13 & 6 & 6/940 (0.64) \\
\hline P410 & 400 & $76(19.0)$ & 19 & 6 & 2 & $2 / 400(0.5)$ \\
\hline Total & 4,200 & $568 / 4,200(13.5)$ & 205/568 (36.1) & $90 / 205(43.9)$ & $38 / 90(42.2)$ & 38/4,200 (0.9) \\
\hline
\end{tabular}

Five genotypes are inbred lines that are used for developing hybrids. The shoots showing the GFP fluorescence contained the GFP gene

showed GFP expression (Fig. 6), and the expression among the seedlings was segregated with a rate of 3:1 (data not shown). $T_{1}$ peppers grown for 1 month after planting were exposed to UV light under a GFP filter, and only transgenic peppers were seen clearly (Fig. 7). As a result, an image of
GFP expression at the whole pepper plant level was obtained for the first time. At later stages, a photo of taller peppers with fruits could not be taken due to lack of a proper filter. However, the green or red fruits taken from transgenic pepper $\left(\mathrm{T}_{1}\right)$ showed GFP expression (Fig. 8). In 
Fig. 4 GFP expression in organs. Pictures were taken using LAS-3000 luminescent image analyzer. Organs from non-GM and GM peppers were compared, and a green color was seen only in GM peppers
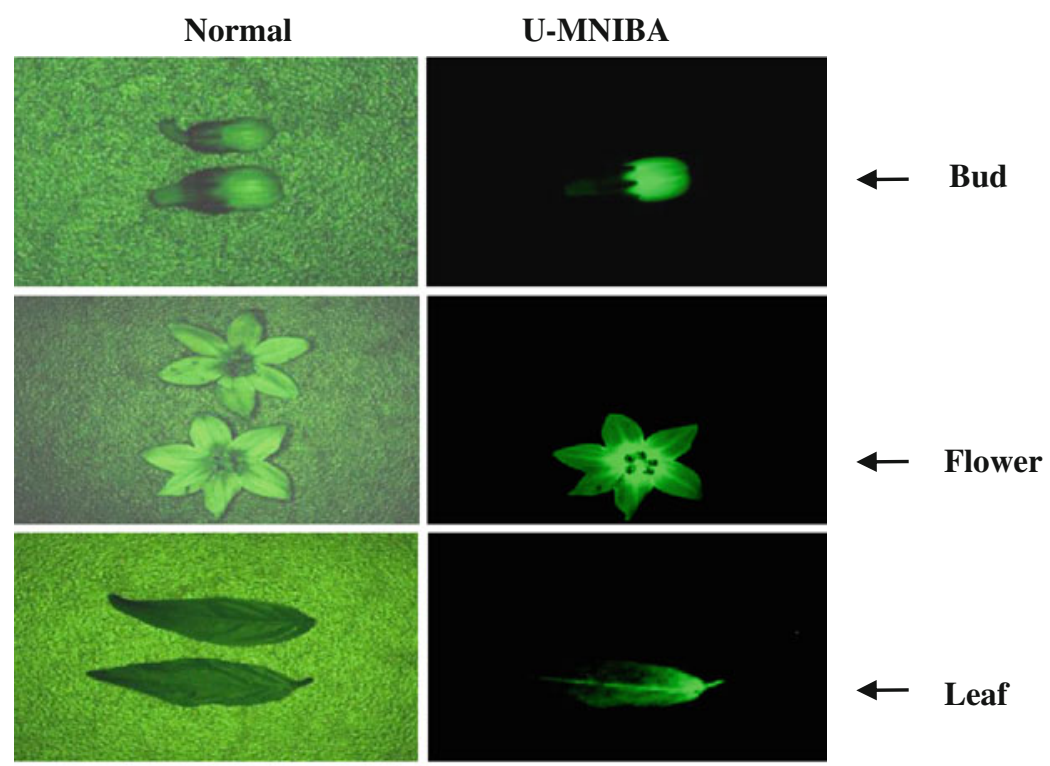

$\longleftarrow \quad$ Leaf
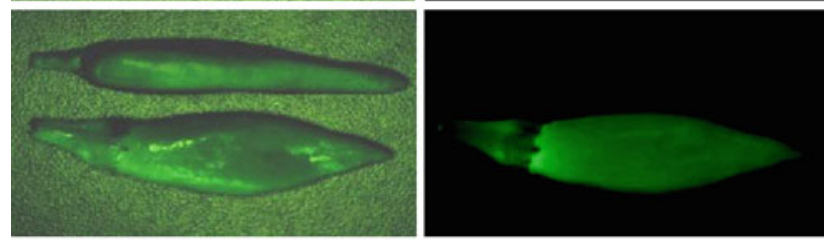

$\longleftarrow \quad$ Green fruit

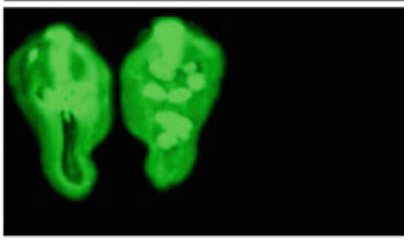

$\longleftarrow \quad$ Green fruit and seeds

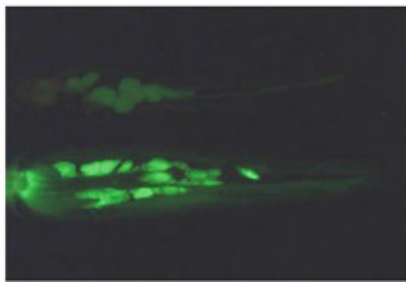

$\longleftarrow \quad$ Red fruit and seeds addition, three $\mathrm{T}_{2}$ seedlings (GFP2, GFP5 and GFP6) were easily observed under a GFP filter (Fig. 9) with segregation rates of 12:3, 11:4, and 11:5, respectively, which are all close to $3: 1$. In comparison, the non-transformed peppers did not show GFP expression (0:15). Therefore, a single copy of GFP gene was segregated in mendelian fashion.

Western blot analysis and RT-PCR analysis

The total proteins isolated from leaves were separated on $12 \%$ SDS-polyacrylamide gels and transferred onto nitrocellulose membranes. Membranes were probed first with anti-GFP, N-terminal antibody (Sigma product number: G1544) followed by the secondary antibody, anti-rabbit IgG (FC) AP conjugate (Promega catalog number: S3731). An antibody-specific protein band of about $30 \mathrm{kDa}$ was visualized in lanes 2, 3 and 5, which contained protein samples of GM pepper, whereas no band was found in lanes 1 and 4, which contained samples of non-GM pepper (Fig. 10a). A sample of $50 \mathrm{ng}$ of the positive GFP purified from bacteria was loaded on the gel and the band was seen at the same size. Figure $10 \mathrm{~b}$ shows the fluorescence between non-GM and GM peppers, and the fluorescent configuration corresponded well with the presence and absence of the protein band (Fig. 10a) as well as transcript levels (Fig. 10c) as visualized by RT-PCR.

\section{Co-transformation of the GFP and CaCS genes}

In order to apply our monitoring system to the transformation of a transgene, the GFP gene was co-transformed along with CaCS (AY819027, provided by Dr. Byung 


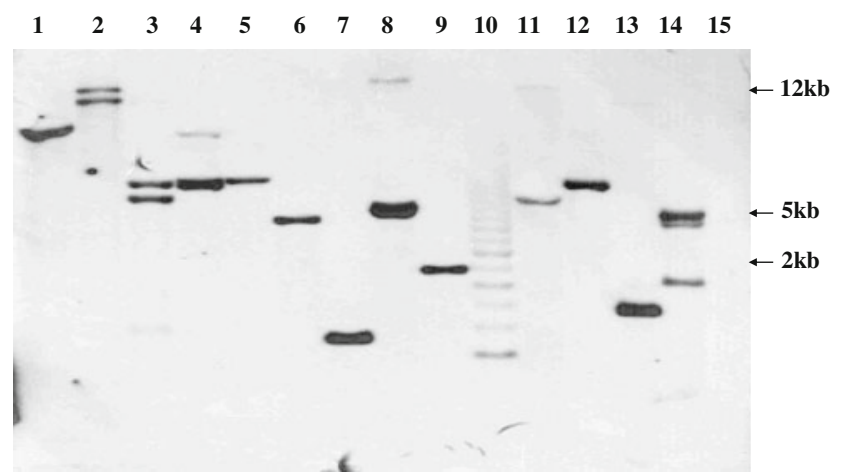

Fig. 5 Genomic Southern blot of $\mathrm{T}_{0}$ peppers. DNA $(30 \mu \mathrm{g})$ was digested with $B a m H I$ and $X b a I$ (enzymes that do not cut the insert) and fractionated on $0.8 \%$ agarose gel. The DNA was blotted into Hybond $\mathrm{N}$ membrane, and the GFP transgene labeled with ${ }^{32} \mathrm{P}-\mathrm{dCTP}$ was hybridized. Lanes $1-14$ transformed $\left(\mathrm{T}_{0}\right)$ peppers; 15 nontransformed
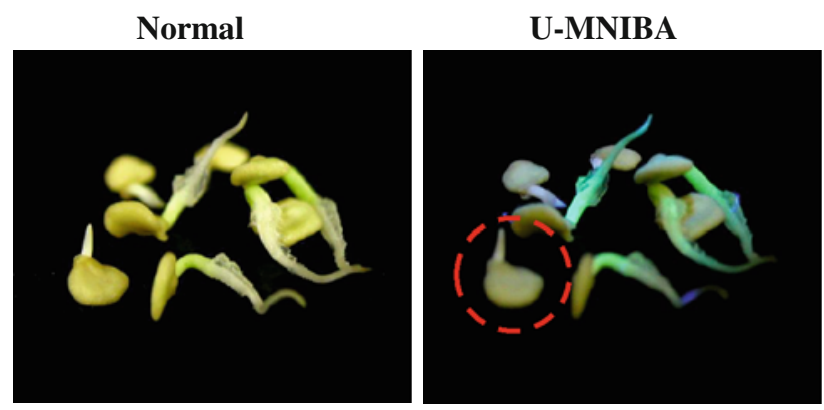

Fig. 6 GFP expression in $T_{1}$ seedlings. $T_{1}$ seeds were germinated and laid onto the GFP device. Pictures were taken with a GFP filter attached to a digital camera. Under the U-MNIBA filter, a red circle showed no fluorescence while others showed GFP expression

Dong Kim), into the pK7WG2D-CaCS vector (data not shown). In this case, the genetic transformation of three sweet pepper varieties (Paprika: Midas, Maximalia and Special) was performed. Paprika was demonstrated as a recalcitrant cultivar by Agrobacterium-mediated transformation. When the callus was exposed to a GFP filter, a bright green color was clearly shown (Fig. 11a). The ratio of callus induction associated with GFP expression was $14.2 \%$ (data not shown), which is about 2.5-times lower than that of chili pepper. Under the same culture conditions, the particular difference between chili pepper and paprika is that the shoots of paprika were not easily induced. The shoots were obtained but the one that showed GFP expression fully was not easily identified. Shoots irrespective of showing GFP expression or not were analyzed by PCR to identify the CaCS gene (Fig. 11b). Only shoots possessing the $\mathrm{CaCS}$ gene were planted in the ziffy pot. The final frequency of the genetic transformation of GFP in paprika was $0.2 \%$ (data not shown). This rate was low probably due to the fact that the genetic transformation method applied to the paprika was the one that was particularly used for chili pepper. Therefore, the genetic transformation method should be modified specifically for paprika. Although the culture conditions for the transformation of paprika were not established, GFP monitoring was able to select the transformed paprika through callus and shoot formation.

Successful application of GFP expression for enhancing transformation rate of pepper crop

The bright green fluorescence emitted by GFP in the callus was visible by microscopy, and the fluorescence was stable and showed little photobleaching. This image did not require staining and allows cells in a living state to be analyzed. This report shows that selection based upon GFP expression in early stage callus was reliable and stable. The callus was selected according to GFP fluorescence, and the final selection efficiency of transformed peppers beginning from the fluorescent callus was found to be $6.7 \%$ $(36.1 \times 43.9 \times 42.2 \%)($ Table 1$)$, which was a remarkable value. Since the callus induction rate itself was not changed when the CIT method was used with the GFP monitoring system or without it, a higher frequency of transformation itself would not be expected. However, this technique could be used to efficiently enhance selection power by monitoring GFP expression at the early stage of tissue development in in vitro culture. Indeed, in this paper, the successful detection of GFP fluorescence in the callus tissue allows the easy finding of the transformed pepper.

The application of GFP to the genetic transformation of crops is a promising tool for enhancing the transformation rate as well as the selection rate (Ghorbel et al. 1999; Elliot et al. 1999; Chung et al. 2000; Vain et al. 1998; Stewart 2001; Majid and Parveez 2007). Additionally, it is believed that GFP could act as an antibiotic selection marker. Callus of barley expressing GFP has been previously shown, and plants were regenerated only by GFP visible selection (Ahlandsberg et al. 1999). Likewise, when the transformation rates of GFP marker and antibiotic selection were compared, GFP usage increased the rice transformation efficiency several-fold (Vain et al. 1998). However, the transformation frequency between visual screening by GFP and hygromycin selection is almost identical. We have observed an equal result from this paper when the transformation rates between GFP screening and the CIT method without GFP (Lee et al. 2009) were compared. The transformation rate itself is not changed but the selection power increased. Sometimes, the GFP-reporting marker only for the selection was not recommended during the selection process. Instead, it is better to conjugate the antibiotic marker so that it would decrease the frequency of false-positive selections or escapes (Tian et al. 1999; 
Fig. 7 GFP expression in $\mathrm{T}_{1}$ whole peppers. Pictures were taken with a GFP filter attached to a digital camera

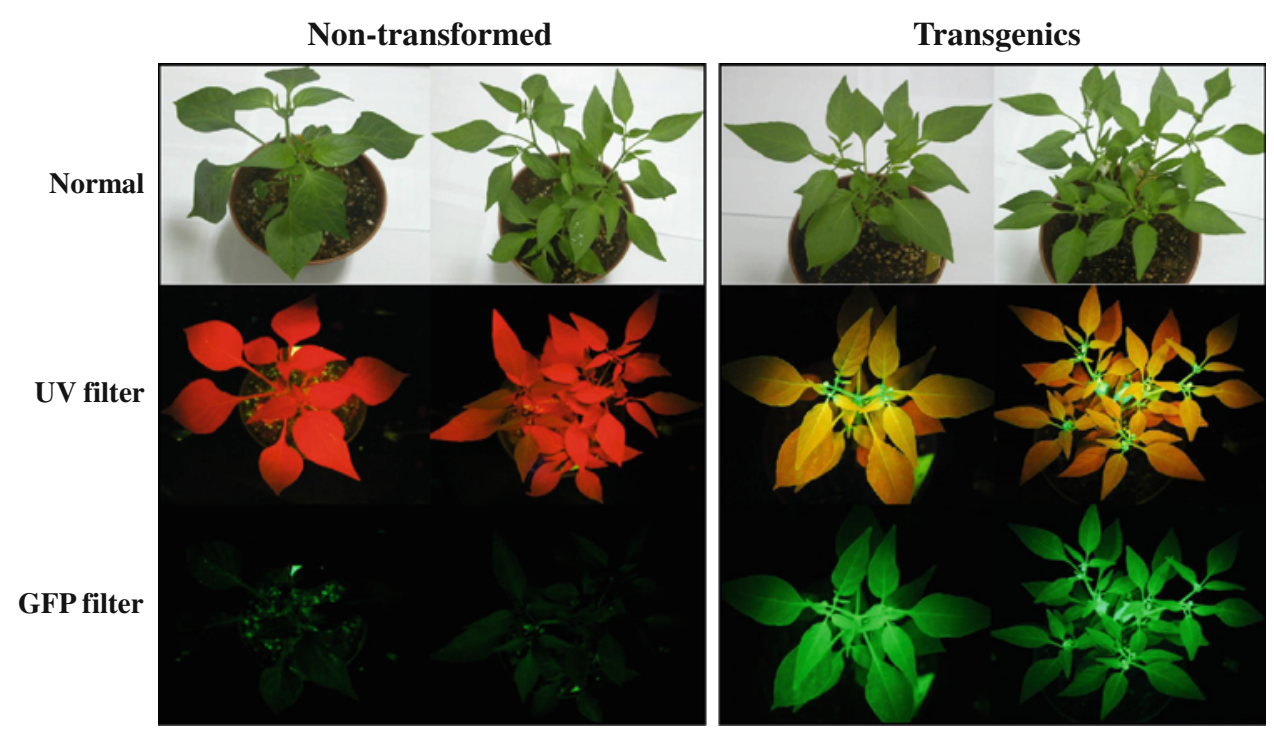

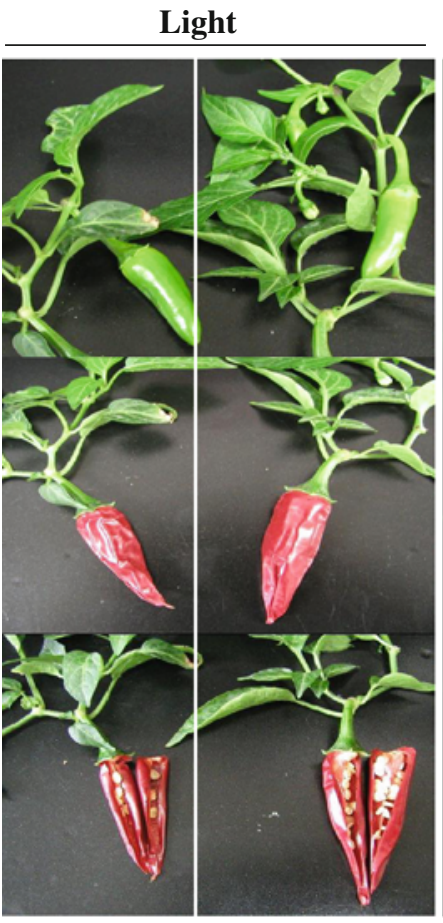

$\mathbf{N}$
$\mathbf{T}$

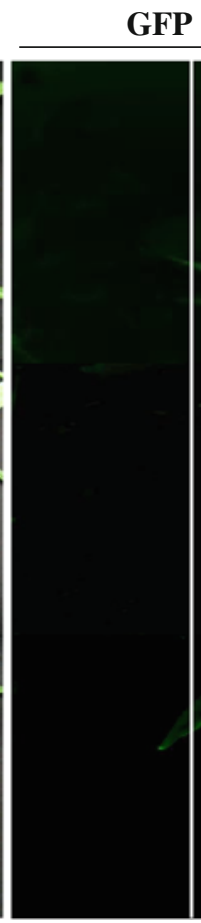

$\mathbf{N}$

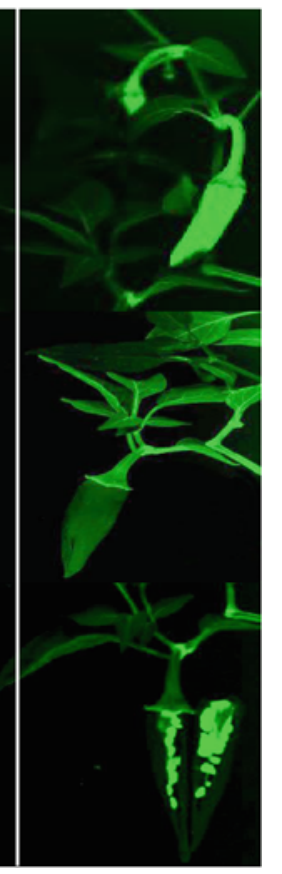

$\mathbf{T}$
A: GFP expression in green fruit

B: GFP expression in red fruit

C: GFP expression in red fruit with seeds
Ghorbel et al. 1999). Here, in this paper, the final transformation rate is $0.9 \%$ (Table 1 ) with GFP screening, and this is not a GFP effect alone. Rather, it is an additive effect of combining GFP screening and kanamycin selection.

To use our GFP selection system for the practical purpose of pepper genetic transformation, co-transformation of the CaCS and GFP genes was performed. The transformed calli of paprika varieties were monitored by GFP expression, and the $\mathrm{T}_{0}$ peppers were easily identified as showing the CaCS transgene by PCR analysis (Fig. 11).

Therefore, it is possible to enhance the selection efficiency of pepper transformation with any transgene by observing GFP expression in the early developmental stage in in vitro culture. Since this monitoring technology with GFP works for even recalcitrant crops such as chili pepper and paprika, this method could be applicable and especially 
Fig. 9 GFP expression in $\mathrm{T}_{2}$ seedlings. $\mathrm{T}_{2}$ seeds were germinated, and pictures were taken with a GFP filter attached to a digital camera

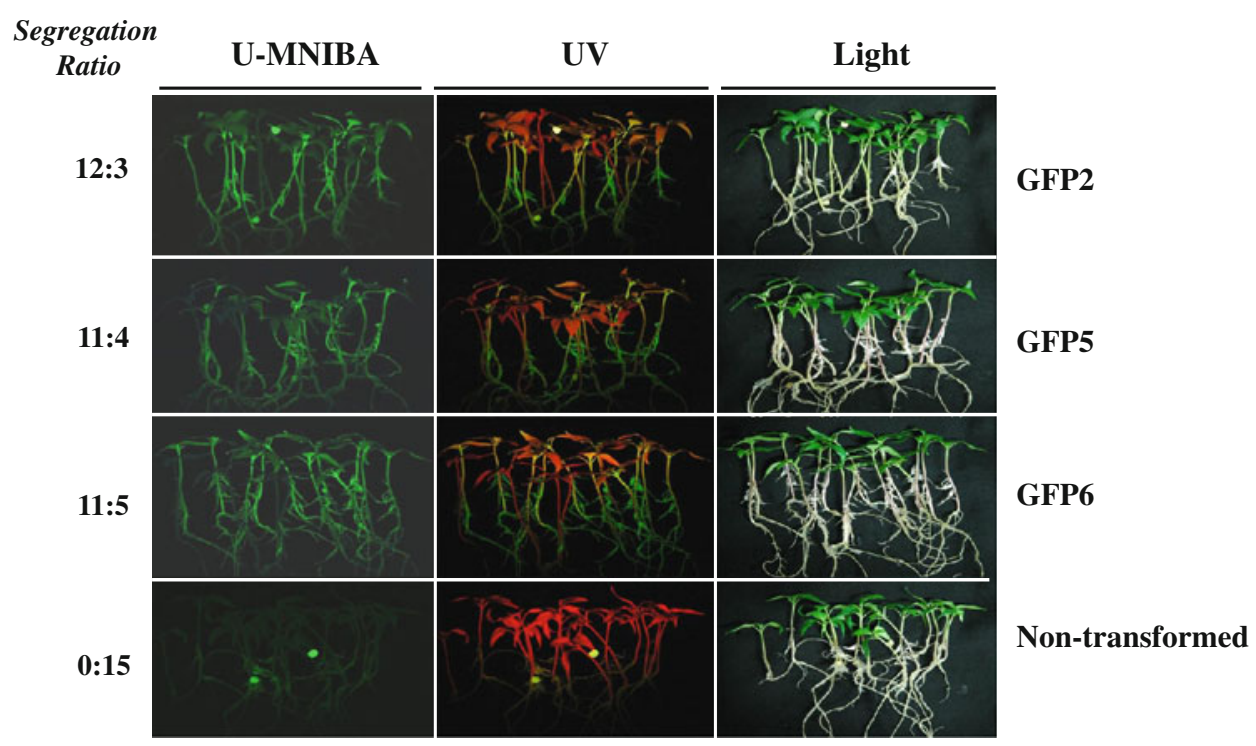

$\mathbf{a}$

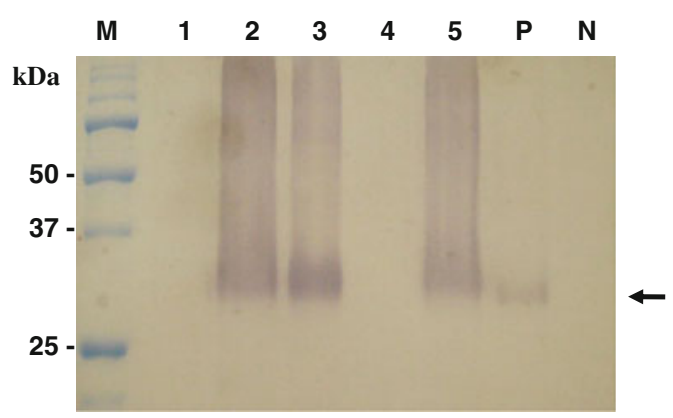

b

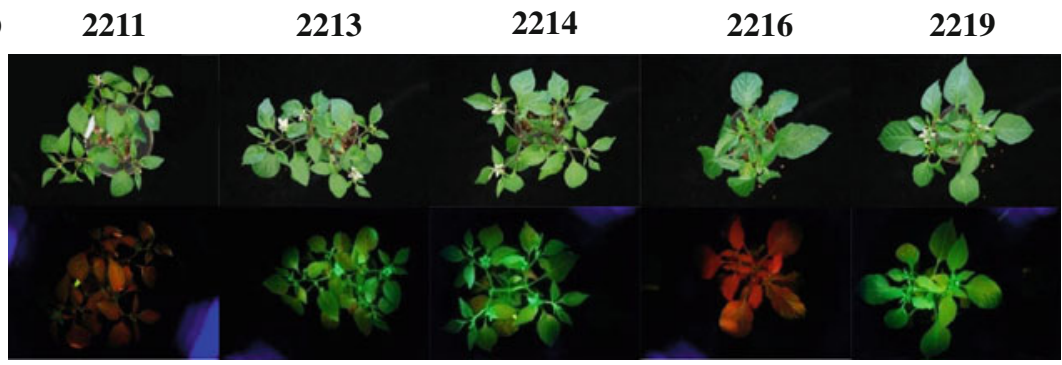

c

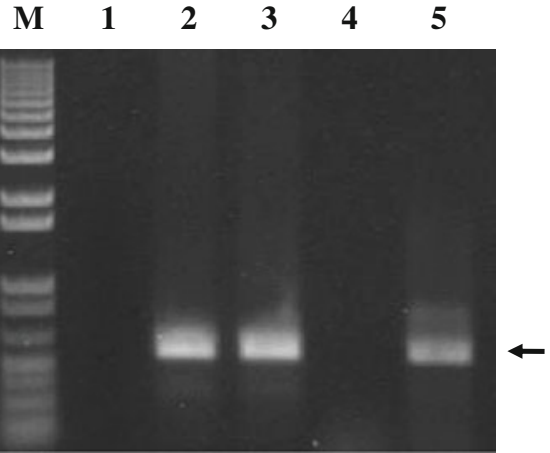




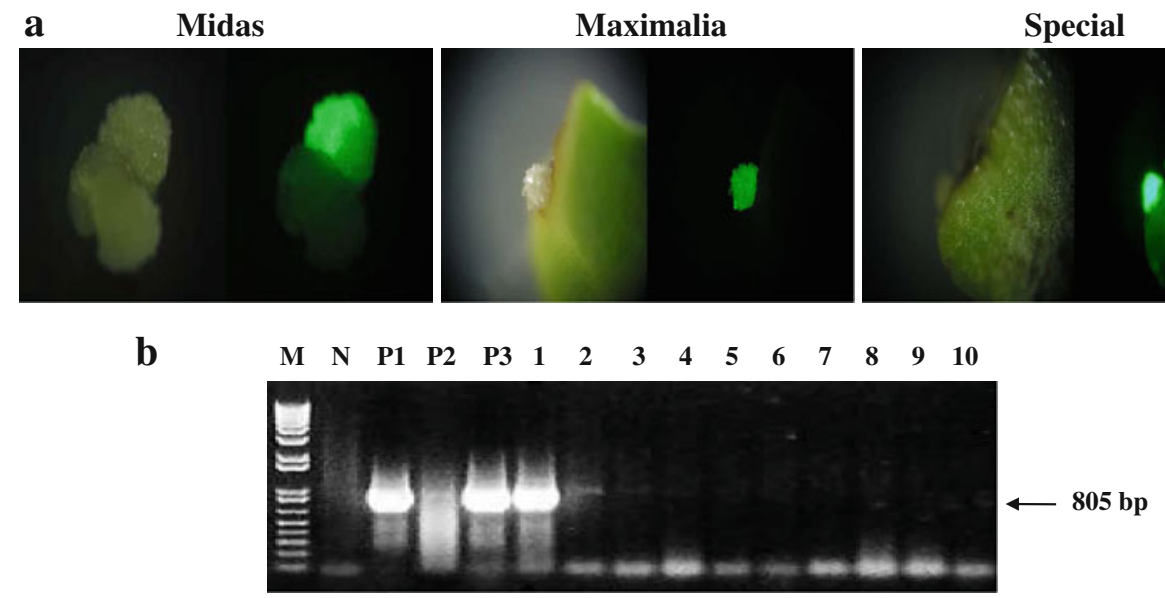

Fig. 11 Sweet pepper transformation with $C a C S:: G F P$. Three sweet pepper varieties (Paprika: Midas, Maximalia, Special) were transformed with a construct containing two genes, $\mathrm{CaCS}$ (encoding capsaicinoid synthetase of Capsicum) and GFP. a The pictures were taken by a fluorescence microscope $(\times 10)$ equipped with a U-MNIBA filter attached to a digital camera. Under the U-MNIBA filter, GFP

helpful to crops in which the transformation rate is extremely low.

Acknowledgments This research was supported from a grant from the Crop Functional Genomics Center of the 21st Century Frontier Research Program funded by the Ministry of Education, Science and Technology of Korea and partially funded by RDA of Korea. We thank Dr. J. K. Kim at Myongji University for technical help concerning the GFP expression picture.

Open Access This article is distributed under the terms of the Creative Commons Attribution Noncommercial License which permits any noncommercial use, distribution, and reproduction in any medium, provided the original author(s) and source are credited.

\section{References}

Ahlandsberg S, Sathish P, Sun C, Jansson C (1999) Green fluorescent protein as a reporter system in the transformation of barley cultivars. Physiol Plant 107:194-200

Chalfie M, Tu Y, Euskirchen G, Ward WW, Prasher DC (1994) Green fluorescent protein as a marker for gene expression. Science 263:725-888

Chomczynski N, Sacchi N (1987) Single step method of RNA isolation by acid guanidinium thiocyanate phenol-chloroform extraction. Anal Biochem 161:156-159

Chung BC, Kim JK, Nahm BH, Lee CH (2000) In planta visual monitoring of green fluorescent protein in transgenic rice plants. Mol Cells 10:411-414

Dixit R, Cyr R, Gilroy S (2006) Using intrinsically fluorescent proteins for plant cell imaging. Plant J 45:599-615

Elliot AR, Campbell JA, Dugdale B, Brettell RIS, Grof CPL (1999) Green-fluorescent protein facilitates rapid in vivo detection of genetically transformed plant cells. Plant Cell Rep 18:707-714

Ghorbel R, Juarez J, Navarro L, Pena L (1999) Green fluorescent protein as a screenable marker to increase the efficiency of generating transgenic woody fruit plants. Theor Appl Genet 99:350-358 expression was seen as a green color. $\mathbf{b}$ PCR was analyzed by primers designed from CaCS. M molecular marker; numbers transformed sweet peppers (1-6 maximalia; 7-9 midas; 10 special), $N$ nontransformed sweet peppers; $P 1$ PCR-positive plant; $P 2 \mathrm{CaCS}$ containing plasmid vector DNA; $P 3$ bacterial cells harboring $C a C S$. Lane 1 shows the positive band

Hanson MR, Köhler RH (2001) GFP imaging: methodology and application to investigate cellular compartmentation in plants. J Exp Bot 52:529-539

Haseloff J, Siemering KR (2006) The uses of green fluorescent protein in plants. In: Chalfie M, Kain SR (eds) Green fluorescent protein: properties, applications, and protocols. Wiley, Hoboken, pp 259-284

Higashijima S, Okamoto H, Ueno N, Hotta Y, Eguchi G (1997) Highfrequency generation of transgenic zebrafish which reliably express GFP in whole muscles or the whole body by using promoters of zebrafish origin. Dev Biol 192:289-299

Lee YH, Kim HS, Kim JY, Jung M, Park YS, Lee JL, Choi SH, Her NH, Lee JH, Hyung NI, Lee CH, Yang SG, Harn CH (2004) A new selection method for pepper transformation: callus-mediated shoot formation. Plant Cell Rep 23:50-58

Lee YH, Jung M, Shin SH, Lee JH, Choi SH, Her NH, Lee JH, Ryu KH, Paek KY, Harn CH (2009) Transgenic peppers that are highly tolerant to a new CMV pathotype. Plant Cell Rep 28:223-232

Leff LG, Leff AA (1996) Use of green fluorescent protein to monitor survival of genetically engineered bacteria in aquatic environment. Appl Environ Microbiol 62:3486-3488

Leffel SM, Mabon SA, Stewart CN Jr (1997) Applications of green fluorescent protein in plants. BioTechniques 23:912-918

Majid NA, Parveez GKA (2007) Evaluation of green fluorescence protein (GFP) as a selectable marker for oil palm transformation via transient expression. Asia Pac J Mol Biol Biotechnol 15:1-8

Murashige T, Skoog F (1962) A revised medium for rapid growth and bioassay with tobacco tissue cultures. Physiol Plant 5:473-479

Park SM, Lee JS, Jegal S, Jeon BY, Jung M, Park YS, Ryu KH, Han SL, Shin YS, Her NH, Lee JH, Yang GY, Harn CH (2005) Transgenic watermelon rootstock resistant to CGMMV (cucumber green mottle mosaic virus) infection. Plant Cell Rep $4: 350-356$

Rosario R, Brini M, Pizzo P, Murgia M, Pozzan T (1995) Chimeric green fluorescent protein as a tool for visualizing subcellular organelles in living cells. Curr Biol 5:635-642

Sambrook J, Fritsch EF, Maniatis T (1989) Molecular cloning: a laboratory manual, 2nd edn. Cold Spring Harbor Laboratory, Cold Spring Harbor, New York 
Sheen J, Hwang S, Niwa Y, Kobayashi H, Galbraith DW (1995) Green fluorescent protein as a new vital marker in plant cells. Plant J 8:777-784

Spellig T, Bottin A, Kahmann R (1996) Green fluorescent protein as a new vital marker in the phytopathogenic fungus Ustilago maydis. Mol Gen Genet 252:503-509

Stewart CN Jr (2001) The utility of green fluorescent protein in transgenic plants. Plant Cell Rep 20:376-382

Tian L, Levee V, Mentag R, Charest PJ, Seguin A (1999) Green fluorescent protein as a tool for monitoring transgene expression in forest tree species. Tree Physiol 19:541-546
Vain P, Worland B, Kohli A, Snape J, Christou P (1998) The green fluorescent protein (GFP) as a vital screenable maker in rice transformation. Theor Appl Genet 96:164-169

Yeh E, Gustafson K, Boulianne GL (1995) Green fluorescent protein as a vital marker and reporter of gene expression in Drosophila. Proc Natl Acad Sci USA 92:7036-7040

Zolotukhin S, Potter M, Hauswirth WW, Guy J, Muzyczka N (1996) A humanized green fluorescent protein cDNA adapted for high level expression in mammalian cells. J Virol 70:4646-4654 